\title{
Designing and Teaching a Curricular Unit to Accomplish the Outcomes Related Learning Objectives
}

\author{
Isabel M. João \\ ADEQ, ISEL - Instituto Superior de Engenharia de Lisboa \\ CEG-IST, Instituto Superior Técnico, Universidade de \\ Lisboa, Portugal \\ ijoao@deq.isel.ipl.pt
}

\author{
João M. Silva \\ ADEQ, ISEL - Instituto Superior de Engenharia de Lisboa \\ CATHPRO/CQE, Instituto Superior Técnico, Universidade \\ de Lisboa, Portugal \\ jmsilva@deq.isel.ipl.pt
}

\begin{abstract}
This paper describes how a curricular unit of Advanced Techniques for Quality was designed in the Quality and Environmental Engineering Master Course to satisfy the outcomes defined in the unit. This paper seeks to (1) explain the steps to take into consideration in the design of a curricular unit, (2) explain the outcomes related learning objectives of the specified curricular unit, (3) identify the instructional techniques that are used in the unit to prepare students to achieve those curricular unit outcomes, as well as the selected assessment methods and (4) describe how an active learning project is used as a teaching learning methodology to help the students to attain the learning outcomes defined in the unit.
\end{abstract}

Keywords - learning outcomes; student-centered learning, learning environments; active learning

\section{INTRODUCTION}

The work of training students and equip them with the attributes specified in the curricular unit learning outcomes starts in the design of the curricular unit where the learning objectives, instructional methods and assessment methods are formulated. This paper describes the steps taken into consideration in the design of a curricular unit discussing and illustrating how the teaching and learning methods are used to align the learning outcomes with the learning objectives of Advanced Techniques for Quality (ATQ). ATQ is a curricular unit of the Quality and Environmental Engineering course, a Master Course of a higher education engineering school in Portugal. The curricular unit outline was designed to guide students towards progressively more deep thinking and practice. The focus in the design of the unit is centred on engaging students in a process that can enhance their learning and include feedback on the effectiveness of their learning effort through the outlined assessment methods prescribed in the unit. According to [1] the quality of the learning outcomes can be guaranteed if the teachers are able to ensure that students have engaged cognitive behaviours. The syllabus of the course, the instructional methods as well as the assessment methods are the main tools available to promote students' engagement.

Learning outcomes (LOs) are statements of what a learner knows, understands and can do on completion of a learning process [2]. When developing a list of LOs, it is important that statements are specific and well defined. The outcomes should explain in a clear and succinct way the specific skills that the students should be able to demonstrate, produce, and know. LOs more clearly connect with how the instructor will evaluate students work to determine if the objectives have been met. The LOs are of utmost importance due to the interplay between students' learning efforts, the syllabus of the unit as well as the instructional and assessment methods $[3,4]$. The LOs may be examined at different levels. At a more comprehensive level the shift to a learner centred approach and to what the learner is expected to know, understand, or can do at the end of a learning process is connected to the development and implementation of most European Education policies at international and national levels [5-7]. The broad consensus among policy-makers, social, education and training partners is mainly due to the relevance of LOs for improving access to and progression within education, training and learning. However, more and more stakeholders warn that the LOs perspective can easily be reduced to mere rhetoric having little effect on education, training and learning practices [5]. At a micro level a key question is the attention to be paid to the LOs to make a difference to individual learners. The LOs perspective must be intrinsically connected with training objectives, the course outline, teaching and learning approaches, as well as assessment methods.

Students usually adopt their own learning approaches to achieve success in the evaluation process and they use the strategies that they think will suffice to meet the assessment requirements [1]. When designing the curricular unit, the teachers need to build learning environments ensuring that students' adaptive responses to the curriculum are consistent with the goals of the teachers when designing the curricular unit [4]. Aligning the learning outcomes with the curriculum of the course will help to clarify the relationship between what the teacher is assessing and what is being taught in the course. At the curricular unit level, the definition of LOs should not be expressed as the rather limited objectives of the taught curriculum in specific subjects because such a narrow, subjectdriven approach does not, in practice, constitute a good learning outcome approach. Confining the LOs only to the subject content steers the intended outcomes for the learner, often supported by traditional, 'pencil-and-paper' types of tests [5]. 
When designing the curricular unit focus must be placed on what the learner will achieve rather than limited to the inputs that the teacher provides (i.e. teacher centred learning approach) The curricular unit design is central to the LOs achievement and so at the class level the teacher must have this in mind and attempt to establish an environment that directs attentions and activities towards the outcomes [8]. Learner-centred teaching methods shift the focus of the activity from the traditional approach where the most class time is spent with the teacher lecturing and the learners watching and listening to an active learning approach engaging the students in the learning process. That requires the students to do meaningful learning activities and think about what they are doing [9]. The teacher's essential task is to get students to engage in learning activities that are expected to result in the students' achievement of the intended LOs [10]. To do so, the main tools available are the topics of the curricular unit itself, the teaching and learning methods, and the assessment practices [4].

\section{CURRICULAR UNIT DESIGN AND IMPROVEMENT}

The curricular unit design includes the definition of the objectives and intended learning outcomes, the syllabus of the unit, the teaching and learning approaches and the assessment methods. The educators are in a powerful position to encourage the students' approaches to learning right from the designing of the curricular unit.

The design of the curricular unit is central to achieve the intended learning outcomes and can be defined as an iterative four-step method. To create and improve a curricular unit to achieve specified outcomes the Plan-Do-Check-Act (PDCA) cycle is suitable. The PDCA cycle popularized by Dr. W. Edwards Deming is a continuous quality improvement model consisting out of a logical sequence of four steps for continuous improvement (Fig. 1). The first step (PLAN) consists of establishing the objectives and plan processes, the second step (DO) consists of implementing the plan and executing the process, the third step (CHECK) consists of studying the actual result, compare to the expected result and the last step (ACT) analyse differences, and define improvement actions [11].

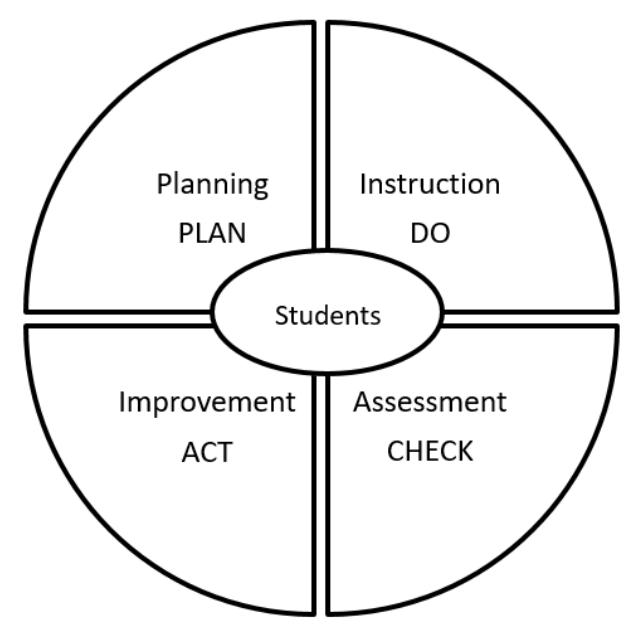

Fig. 1. PDCA cycle to design and improve a curricular unit.
The cycle can be used in the context of the design and improvement of a curricular unit according to the four steps as described in Table I.

\section{A. Planning}

The first step consists of defining learning outcomes based on educational objectives and identifying the curricular unit contents (syllabus of the course) focusing the unit in outcomes format, defining the instructional methods and assessment tools aligned with the intended learning outcomes. It is advantageous to rewrite the content of the unit in outcomes format such that it becomes clear to the students what they are expected to understand and do. The main goal is always to maximize the students learning outcomes. Biggs' 3P model of learning and teaching [1] shows how students' factors interact with the teaching context during the learning activities and lead to the attainment, or non-attainment, of the learning outcomes. The model points out the responsibility of the teacher in the design and structure of the learning environment, but also the role of the students due to their responsibility for engaging appropriately with the activities.

The syllabus of the curricular unit must be developed having in attention some curriculum design principles as established by [4]. The development should be in a way that provides students with learning resources, tasks and experiences that are real world and authentic. That requires students to use and engage with progressively higher order cognitive processes, which are aligned with each other, and with the expected learning outcomes providing challenge, interest and motivation to learn. When structuring the subjects of the curricular unit and defining the expected learning outcomes the teachers must focus on learners demonstrating subject specific competencies, but also certain cross cutting competences such as communication, collaboration, creativity, critical thinking and so on. The curricular unit contents must also be aligned with the objectives of the master course at a higher level. The objectives are statements that communicate how the curricular unit fulfil its

TABLE I. CURRICULAR UNIT DESIGN AND IMPROVEMENT

\begin{tabular}{|c|c|}
\hline Steps & description \\
\hline Planning & $\begin{array}{l}\text { a. Learning outcomes definition based on educational } \\
\text { objectives } \\
\text { b. Syllabus creation based on educational objectives } \\
\text { and learning outcomes } \\
\text { c. Definition of teaching methodologies (instructional } \\
\text { methods) aligned with the intended learning outcomes. } \\
\text { d. Definition of assessment methods aligned with the } \\
\text { intended learning outcomes }\end{array}$ \\
\hline Instruction & e. Implementation of the teaching-learning methods \\
\hline Assessment & f. Implementation of the evaluation methods \\
\hline Improvement & $\begin{array}{l}\text { g. Reframing objectives } \\
\text { h. Improve the alignment of objectives with learning } \\
\text { outcomes } \\
\text { i. Modify the instructional methods to improve the } \\
\text { alignment with the learning outcomes } \\
\text { j. Adapt teaching-learning methods } \\
\text { 1. Adjust/modify the methods of assessment }\end{array}$ \\
\hline
\end{tabular}


needs and to have a clear idea of what we want our students to learn on a topic by topic basis, we need to have a further idea as how well we want each topic to be understood. Some topics are more important than others. In some topics the students need to know some basic information and know where to go to look it up if they need any further information on that topic in the future. For other topics it is required a deeper level of understanding and they must be understood at a level that allows the students to put that topic to work. The topics must be stated in terms of what the students are required to do and not concerning what the teachers must cover in class. The revised Bloom's Taxonomy of Educational Objectives is one traditional framework for structuring learning outcomes. Reference [12] present a revision of the original Bloom's taxonomy [13], and redefines the cognitive domain as the intersection of the cognitive process dimension and the knowledge dimension. This taxonomy provides a framework for determining and clarifying learning outcomes. The cognitive process dimension represents a continuum of increasing cognitive complexity-from lower order thinking skills to higher order thinking skills. Reference [12] identify nineteen specific cognitive processes that further clarify the scope of the six categories (i.e. remember, understand, apply, analyse, evaluate and create).

\section{B. Instruction}

The instruction consists in the selection and implementation of the teaching-learning methods so that the detailed content could be delivered to facilitate the students' achievement of the outcomes related learning objectives. It is very important that students know on the first day of the course, what they are expected to perform and the more training they acquire in doing such activities the greater the probability that they will attain the desired skills and aptitudes $[14,15]$. The contents of the curricular unit must provide the students with learning materials, tasks and experiments that require students to actively participate and to engage with higher order thinking skills. The instructional methods of the curricular unit should be relevant to the goal of the course and the topics should be sequential, interlinked and aligned with each other and with the learning outcomes.

The curricular unit should be designed to provide challenge, interest and motivation to learn. The instructional methods to use play an important role in the design of the educational activities, environments and experiences. Instructional methods depend on several factors such as the objectives to accomplish, the content, the resources, and so on. A single method is not able to meet all the outcomes related learning objectives or accommodate all learning styles at once. According to [16] learning styles of most engineering students and teaching styles of most engineering professors are incompatible in several dimensions. Most engineering students are visual, sensing, inductive, and active, and some of the most creative students are global. However, if the engineering education practice is mainly auditory, abstract (intuitive), deductive, passive, and sequential it will correspond to a discrepancy between instructional methods and students learning styles. These mismatches lead to poor student performance, pedagogical frustration, and a loss to society of many potentially excellent engineers.
Nowadays the lecture method is a relatively poor instructional approach for maintaining students' attention [17]. In classes where teachers make excessive use of PowerPoint presentations few students are usually visibly engaged in taking notes. In some classes it is not uncommon, during teacher presentations, to see the students instant messaging on their cell phones, playing on a computer or simply daydreaming. This is in accordance with many papers on teaching where the authors claim that students' attention tend to decline after the first 10-15 minutes of a lecture (e.g. $[18,19])$. The interest demonstrated by the students with a teacher centred lecture tends to decline with time even if the topic is interesting and delivered with clearness and enthusiasm, and so the teacher needs to develop pedagogical strategies to maintain the students' interest in the classroom [20]. There are also a range of activities that can be scheduled outside the classroom with group work-based learning, peer teaching and independent learning, all of which are a rich source of relevant learning activities [1]. Active learning instructional strategies are very important to involve students in doing things and thinking about the things they are doing [21]. The teacher challenge is to stimulate the students to actively engage in the learning process and be able to develop their ideas and be creative, think more critically and become better prepared to solve problems. The adoption of an active learning approach requires that the teacher adopt a student-centred approach [22] where the teaching and learning emphasize the student activity and responsibility in learning. Some characteristics of these student-centred teaching methods are: (1) the activity and independence of the student, (2) the coaching role of the teacher, and (3) knowledge which is regarded as a tool instead of an aim [23].

\section{Assessment}

The assessment methods are a key concern because the assessment practices must be aligned with what the teachers want the students to learn. According to [24] and as far as the students are concerned they will learn what they think they will be assessed on and not necessarily what is in the syllabus. When designing the curricular unit, it is important to make sure that the assessment task is aligned with what the teachers want the students to accomplish. To the teacher the assessment is at the end of the teaching learning sequence (i.e. objectives, intended learning outcomes, teaching activities, assessment), while for the students it is at the beginning because they will learn based on what they think they will be evaluated and not based on the syllabus or even on what has been covered in class [1]. The assessment and evaluation consist in selecting and implementing the methods that will be used to determine whether and how well the objectives have been achieved and interpreting the results. The teachers need to select the best ways of finding if the students achieve the intended learning outcomes of the unit. Multiple choice tests and written exams may be adequate for students demonstrating subject specific competencies, but concerning certain cross cutting competencies, such as oral communication, collaboration, creativity, critical thinking and so on, some other assessment methods could reveal more adequate (e.g. seminars, presentations, projects, portfolios). 


\section{Improvement}

The curricular unit improvement is very important, so restructuring and adapting when necessary is vital so that the focus always be in the students' learning. For example, the assessment methods should give emphasis on the support of students' achievement rather than simply on a measurement. If we strictly envisage the assessment as the measurement of students' learning, then the main purpose is to provide information to others about the extent to which students have learned something or how their work compares with that of other students. In a wider perspective, we can view the assessment as a way to help students to improve their learning. From this perspective more than "assessment of learning" we can talk about "assessment for learning" by helping the students identify any gaps between current performance and required achievement. According to [25] the assessment reveals when an outcome related learning objective has not been satisfactorily achieved and the nature of the failure may suggests changing the objective or modifying the instruction used to address it. Likewise, as the quality of the instructional program improves, new objectives may be formulated to include higher levels of achievement and the instruction and assessment modified accordingly.

\section{CURRICULAR UNIT OF ADVANCED TECHNIQUES FOR QUALITY}

Advanced Techniques for Quality (ATQ) is a curricular unit of the Quality and Environmental Engineering Master Course at ISEL, a Higher Education Engineering School from the Polytechnic Institute of Lisbon. The first edition of the course, took place in the winter semester of 2015-2016. The unit covers topics related to product and process design control and improvement. The objective is to introduce the experimental design and the types of problems in which designed experiments are useful, specially its contribution to the design of more reliable products with greater performance and easier to manufacture. The techniques discussed are very useful in the design and optimization of products and processes. They are used in many industries and are essential for engineers because its correct use is a key factor for better quality and productivity.

\section{A. Outcomes related learning objectives}

The learning objectives of the curricular unit and the course outline can be written in terms of intended learning outcomes format. The learning outcomes of the unit can be related, in a table, with the specific unit learning objectives such that it becomes clear to the students what they are expected to achieve upon completing the curricular unit. Keeping this in mind the learning objectives of ATQ were formulated as well as the curricular unit learning outcomes to address the educational objectives of the unit. An evaluation table was built to simplify the understanding of the relationship between the unit learning outcomes and the learning objectives (Table II). The creation of a table to relate the objectives and the intended learning outcomes requires the teachers to look in depth for the objectives of the curricular unit and align them with the learning outcomes. The intended learning outcomes of ATQ are:
TABLE II. OUTCOMES RELATED LEARNING OBJECTIVES OF THE UNIT

\begin{tabular}{|c|c|c|c|c|c|c|c|}
\hline learning objectives of ATQ curricular unit & \multicolumn{7}{|c|}{ Outcomes } \\
\hline $\begin{array}{l}\text { Define in a few sentences, quality, quality } \\
\text { dimensions quality improvement as well as the usual } \\
\text { quality terminology according to ISO } 9000\end{array}$ & & & $\mathbf{x}$ & $\mathbf{x}$ & & & \\
\hline $\begin{array}{l}\text { Explain and discuss methods for quality control and } \\
\text { improvement, six sigma quality performance, quality } \\
\text { and productivity. }\end{array}$ & & & $\mathbf{x}$ & $\mathbf{x}$ & & & \\
\hline $\begin{array}{l}\text { Illustrate quality and variety, functional variability } \\
\text { and quality problems and compare quality } \\
\text { philosophies (e.g. Crosby, Taguchi) }\end{array}$ & & & $\mathbf{x}$ & $\mathbf{x}$ & & & \\
\hline $\begin{array}{l}\text { Compute the economy resulting from reduction of } \\
\text { variation, perform quality assessment and } \\
\text { manufacturing tolerances and relate loss and process } \\
\text { capability. }\end{array}$ & $\mathbf{x}$ & & & $\mathbf{x}$ & & & \\
\hline $\begin{array}{l}\text { Explain and discuss how the analysis of variance } \\
\text { (ANOVA) is used to test hypotheses about the } \\
\text { equality of more than two means }\end{array}$ & & & & $\mathbf{x}$ & & & \\
\hline $\begin{array}{l}\text { Explain and discuss how designed experiments can } \\
\text { be used to improve product/process performance. }\end{array}$ & & & $\mathbf{x}$ & $\mathbf{x}$ & & & \\
\hline $\begin{array}{l}\text { Formulate a problem, plan the experiment, and } \\
\text { perform a designed experiment. }\end{array}$ & $\mathbf{x}$ & $\mathbf{x}$ & & $\mathbf{x}$ & $\mathbf{x}$ & $\mathbf{x}$ & $\mathbf{x}$ \\
\hline $\begin{array}{l}\text { Decide how to select a factorial and fractional } \\
\text { factorial design and perform experiments, estimate } \\
\text { effects, analyze data from the designed experiment, } \\
\text { determine the optimum conditions and check the } \\
\text { model adequacy. Interpret and criticize the results. }\end{array}$ & $\mathbf{x}$ & $\mathbf{x}$ & & $\mathbf{x}$ & $\mathbf{x}$ & $\mathbf{x}$ & $\mathbf{x}$ \\
\hline $\begin{array}{l}\text { Explain and discuss the use the response surface } \\
\text { approach to optimizing processes. Apply the method } \\
\text { of steepest ascent, how to analyze a second-order } \\
\text { response surface model }\end{array}$ & $\mathbf{x}$ & $\mathbf{x}$ & $\mathbf{x}$ & $\mathbf{x}$ & & & \\
\hline $\begin{array}{l}\text { Construct and interpret contour plots and response } \\
\text { surface plots }\end{array}$ & & & $\mathbf{x}$ & $\mathbf{x}$ & & & \\
\hline $\begin{array}{l}\text { Explain and discuss the use of robust parameter } \\
\text { design (Taguchi parameter design). Build and solve } \\
\text { response models to conduct process robustness } \\
\text { studies }\end{array}$ & $\mathbf{x}$ & $\mathbf{x}$ & $\mathbf{x}$ & $\mathbf{x}$ & & & \\
\hline
\end{tabular}

- Outcome (1) - Ability to apply statistical experimental design techniques in the design, development and optimization of products and processes.

- Outcome (2) - Ability to design and conduct experiments as well as analyse and interpret data.

- Outcome (3) - Understand and comprehend the quality terminology, quality dimensions, six sigma quality improvement tools.

- Outcome (4) - Ability to communicate effectively in both writing and speaking in in the contexts of applying the design of experiments principles and techniques to the identification, formulation and solution of engineering problems.

- Outcome (5) - Ability to use statistical experimental design to solve real problems

- Outcome (6) - Ability to work in teams.

- Outcome (7) - Demonstrate critical and analytical skills in the use of statistical experimental techniques concerning product and process performance and optimization.

The specific objectives, directly related with the specific learning outcomes to be achieved by the students are defined in 
terms of the revised six levels of Bloom's Taxonomy of Cognitive Objectives [12]. The first three levels concerning understanding, comprehension and application are commonly known as lower-level skills (i.e. levels where students are expected to repeat memorized information, paraphrase text, explain concepts and apply course material to solve straightforward problems). The last three levels are concerning to the analysis, synthesis and evaluation, commonly known as higher-level skills (i.e. levels where students are expected to solve real problems, design experiments, choose among alternatives and justify the choice, optimize products/ processes, make judgements about the impact of the decisions). The learning objectives were written in a clear language in the present tense and the learning requirements identified to guide the assessment practices which also guide the approaches to teaching materials, activities and instructional methods.

The initial learning objectives of the curricular unit described in Table II are mainly related with low order skills as denoted by the verbs define, explain, illustrate, compute. As the contents of the curricular unit are being transferred and assimilated by the students, the learning objectives also evolve to high level skills with verbs as formulate, plan, perform, decide, determine, interpret, criticize.

Looking in depth to the different abilities represented in the learning outcome statements also leads to a deep thinking concerning the instructional methods to use and the assessment methods not only with the strict objective of measuring the students learning but also with the objective of helping students to identify their gaps in knowledge.

\section{B. Aligning teaching and learning methods to outcomes related learning objectives}

The course is planned for fifteen weeks with two sessions per week and a total of 60 hours/per semester. Starting in the first week of the course the instructional methods take the form of mini lectures and supplementary readings, classroom exercises and homework problems. As the weeks' goes by, other teaching and learning methods are used corresponding to lecture activities were real or simulated experimental data may be provided in classroom exercises, or in homework problems, where the students are asked to perform data analysis and interpretation of the results. We would not like to see our teaching and learning activities restricted to lecture and tutorial to clarify and extend because we were afraid that the students would get away with passive listening and selectively memorizing. For us as teachers, it would be important to create some active learning instructional strategy to engage students to creatively formulate a problem, plan execute an experiment and interpret and discuss the results. The main objective of the activity is to encourage the students to think creatively, to collaborate, think critically and discuss with teachers and peers. The active learning instructional strategy to create should allow tasks to be completed by students either in class and/or out-ofclass, working as a team, with the use of some statistical software tools or only with excel. The active learning instructional and assessment methods to select should be able to engage the students in the learning process and contribute to the achievement of the intended learning outcomes especially those related with cross cutting competencies such as communication, collaboration, creativity and critical thinking. For these reasons, an active learning project was introduced as an instructional and assessment activity to achieve those objectives.

\section{The role of the curricular unit assessment}

The assessment of the unit includes two short tests during the semester to allow students to demonstrate what they know and if they are achieving the desired learning outcomes. The two short tests weight a total of $20 \%$ of the final grade and the main objective is to allow the teacher to monitor students' learning along the semester to adapt the teaching strategies to the class. The objective is mainly to facilitate the learning of all the students to fit the students learning needs, offering a variety of learning experiences to meet the learning needs. The elaboration of the short tests takes into consideration the evaluation of the students' knowledge in specific subjects of the curricular unit and the analysis of the progression of the students' knowledge and abilities. The short tests also evaluate if the students communicate effectively in writing style in the contexts of applying the design of experiments principles and techniques to the identification, formulation and solution of engineering problems.

Another assessment tool is a summative test that contributes to $40 \%$ of the final grade and occur at the end of the semester and measures the extent to which the students have achieved the main desired learning outcomes. Through this perspective the summative assessment's main purpose is to provide information about the extent to which students have learned the contents and how their work compares with that of other students. This individual component of the evaluation also accomplishes the objective of having a standardized component of the evaluation process so that it will be easier to monitor over time.

By analysing the outcomes related learning objectives, we felt the need to have another assessment tool that allowed students to reach other learning outcomes. One of such outcomes is the ability to communicate orally and the ability to speak in in the contexts of applying the design of experiments principles and techniques to the identification, formulation and solution of engineering problems. Another outcome is related to the demonstration of critical and analytical skills in the use of statistical experimental design techniques concerning product and process performance and optimization. The introduction of a project as an assessment technique will fill that gap and allow students to improve their own learning. The project would also be very effective as a strategy to promote active learning as an instructional activity involving students doing things and thinking about the things that they are doing. The introduction of a project chosen by the students engages them in higher order thinking tasks as planning, analysis, synthesis and evaluation [26]. 


\section{ACTIVE LEARNING PROJECTS}

After the first seven weeks of classes the students start the project. The students are usually grouped in teams of three or four elements from classes with reduced number of students (i.e. up to twenty students). They are asked to pick a subject of their interest and propose the topic, plan the experiments, perform the experiments and analyse and criticize the results. Reference [27] present a "paper helicopter experiment" which can be easily understood by the students, providing a stimulus for the students to think about their own project. The article is delivered to each group of students at the beginning of their work and serve as a trigger to the project development.

The objective is that students design the experiments to perform without receiving instructions on how to perform the experiments. The students must design the experiments by themselves, and engage in the hands-on learning process to achieve the specific goals. Each group of students develops each own project and after seven weeks they present the project in a session. The discussion of the findings is made with the teachers and peers in a session of twenty minutes per group including 5 minutes of discussion. In this session each team presents the developed work and explain all the steps of the project. As part of the presentation, the students also play a video with 3 to 5 minutes long where they present the step by step procedure and illustrate the details of the experiment which makes easier the discussion and debate with the teachers and colleagues. The project is a very useful activity to get students energized and engaged in the hands-on learning process. The video can also be regarded as an instructional strategy that the students can use to explain the project to peers and to the teachers allowing for a better understanding of the project. At the beginning the students develop all the ideas about the problem, the specific objectives of the experiment and start with the idea of the project (i.e. recognition and problem statement). Then they choose all the factors to be varied in the experiment, the work ranges over which the factors will be varied, and the specific levels to perform the runs. In selecting the response variable, the students should be certain that the variable really provides useful information about the process under study. The choice of the experimental design the students consider the number of replicates (i.e. the sample size), the selection of a suitable run order for the experimental trials, and whether or not blocking or other randomization restrictions that may be involved. The main objective is that the students are actively engaged in the learning process and that each group can develop their own ideas and creative thoughts about the project to develop. When running the experiment, the students can realize the importance of a careful monitorization of the process to ensure that everything is being done according to plan. As an example of the type of projects made by the students, five samples from 2015/2016 and 2016/2017 are illustrated in Fig. 2.

Although in some cases, students might have prior expectations regarding the results of the experiments, they were not supposed to make predictions before running the experiments. Only after performing and analysing the experiment the students were able to fit a regression model to the data and use the model to obtain the predicted values at any point in the region of experimentation. By presenting the project
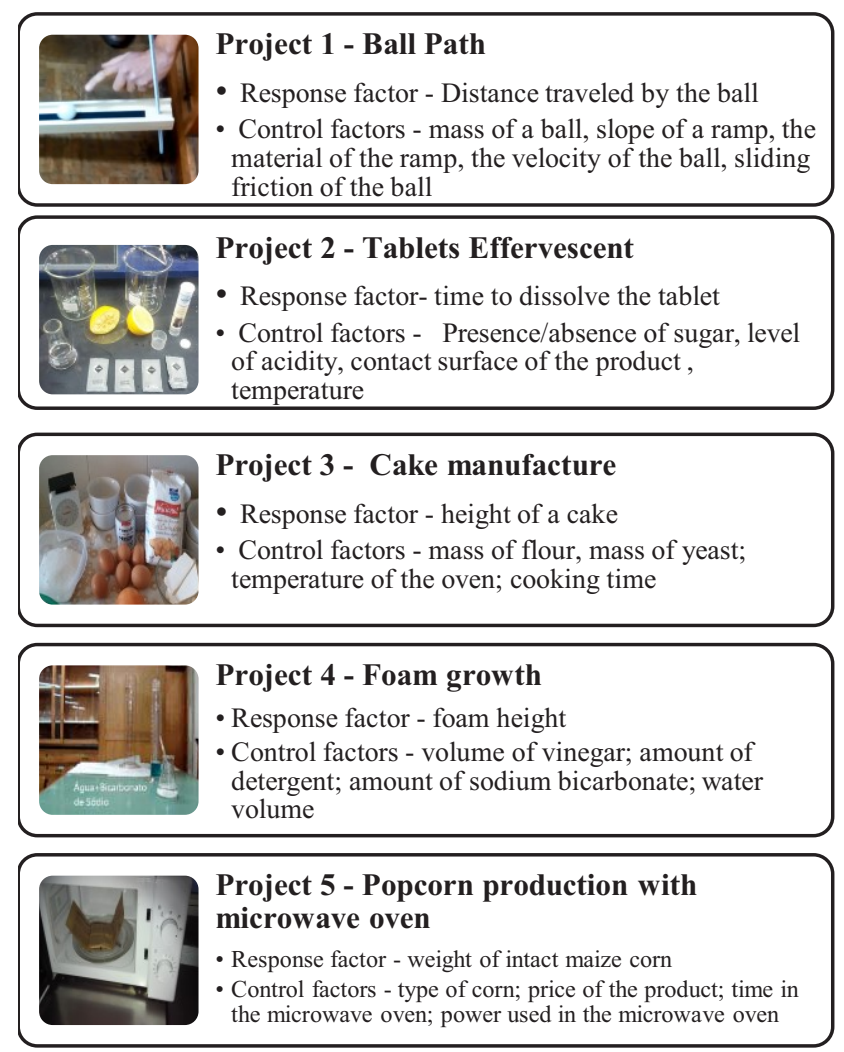

Fig. 2. Examples from the projects developed by the students in the academic years 2015-16 and 2016-17.

to the teachers and peers the students were also able to improve their oral communication skills.

From the teachers' perspective the communication is one of the key roles of the engineer. The quality engineer must be able to explain the results of a complex analysis to a customer with little knowledge on the subject. Teachers must take this into account when devising an assessment strategy for a curricular unit. Another important thing was the enthusiasm of the students in presenting their work and video of their projects. It was very interesting to note that despite the concepts were previously taught in classes using a combination of techniques (e.g. lectures followed by a practice, case studies, computed guided sessions) the students were much more involved with the project and motivated to put in practice the statistical tools. The introduction of a project chosen by the students engage them in higher order thinking tasks as planification, analysis, synthesis and evaluation. The presentation of the projects discussion of the results with teachers and peers allowed students to demonstrate their critical and analytical skills in statistical experimental design for product and process improvement.

\section{CONCLUSIONS}

Teaching and learning takes place in a context which extends beyond the classroom. The learning objectives, assessment methods, and instructional techniques should be formulated to address the intended learning outcomes of the curricular unit. Such a formulation is a necessary condition for addressing the 
curricular unit goal. The Plan-Do-Check-Act (PDCA) cycle is a suitable tool to improve the teaching-learning process and raise the level of achievement of the intended learning outcomes of the curricular unit. Looking at those four steps will address the requirement for a careful design of the curricular unit and for the continuous curricular unit improvement.

The paper exemplifies the PDCA cycle in the context of ATQ, a curricular unit devoted to product and process design improvement with statistical designed experiments. The example provided shows the relevance of the four steps in the design and improvement of a curricular unit and the relevance of the instructional strategies and assessment methods to align the intended learning outcomes with the specific objectives of the curricular unit facilitating the students' process of achieving the learning outcomes. The paper highlights the relevance of the teaching learning strategies and assessment methods in the alignment with the learning outcomes. Some specific outcomes are related with the technical issues of the unit and refer to learning of knowledge, skills, and/or attitudes related with quality engineering while some more generic outcomes that are independent of the technical issue are also relevant (e.g. oral communication, work in teams, critical thinking).The project was used as an active learning instructional and assessment method to engage the students in the learning process and contribute to the achievement of the intended learning outcomes, especially those related with cross cutting competencies such as communication, collaboration and critical thinking. The students' interaction enhances the chances of meeting the outcomes such as oral communication skills, teamwork and collaborative practice.

The reason to introduce a student-centred approach is also related to the fact that this new generation of students that were born in the 1990's have different learning styles and different characteristics (e.g. their preference for experiential learning, their digital literacy, the need for interactivity) [28]. The introduction of a project chosen by the students engages them in higher order thinking tasks as planning, analysis, synthesis and evaluation and showed to involving students doing things and thinking about the things that they are doing.

\section{REFERENCES}

[1] J.B. Biggs, Teaching for quality learning at university, $2^{\text {nd }}$ ed.. Buckingham: Open University Press/Society for Research into Higher Education, 2003.

[2] Cedefop -European Centre for the Development of Vocational Training, Learning outcomes approaches in VET curricula. A comparative analysis of nine European countries. Luxembourg: Publications Office of the European Union, 2010.

[3] W.H. Leonard, "How do college students best learn science? An assessment of popular teaching styles and their effectiveness," Journal of College Science Teaching, vol. 29, no. 6, pp. 385-388, May 2000.

[4] N.M. Meyers and D.D. Nulty, "How to use (five) curriculum design principles to align authentic learning environments, assessment, students' approaches to thinking and learning outcomes," Assessment \& Evaluation in Higher Education,vol. 34, no. 5, pp. 565-577, October 2009.

[5] Cedefop - European Centre for the Development of Vocational Training, The shift to Learning Outcomes, Policies and Practices in Europe. Luxembourg: Publications Office of the European Union, 2009.
[6] Cedefop - European Centre for the Development of Vocational Training, Brefing note: Qualifications Frameworks in Europe, Developments 2016. Office for Official Publications of the European Communities, December 2016.

[7] CRE, The Bologna Declaration, Conference of Rectors in Europe, 19 June 1999 .

[8] T. Hussey and P. Smith, "The Uses of Learning Outcomes," Teaching in Higher Education, vol. 8, no. 3, pp. 357-368, 2003.

[9] M. Prince, "Does active learning work? A review of the research," Journal of Engineering Education, vol. 93, no. 3, pp. 223-231, July 2004.

[10] T.J. Shuell, "Cognitive conceptions of learning, " Review of Educational Research, vol. 56, no. 4, pp. 411-436, December 1986.

[11] W.E. Deming, Out of the Crisis, MIT Press. Cambridge, MA, 1986.

[12] L. Anderson, and D.A. Krathwohl, Taxonomy for Learning, Teaching and Assessing: A Revision of Bloom's Taxonomy of Educational Objectives. New York: Longman, 2001.

[13] B Bloom, M. Englehart, E. Furst, W. Hill, and D. Krathwohl, Taxonomy of educational objectives:The classification of educational goals. Handbook I: Cognitive domain. New York, Toronto: Longmans, Green, 1956.

[14] N.E. Gronlund and S.M. Brookhart, Gronlund's Writing Instructional Objectives, 8th ed.. Norman E. Gronlund, 2008.

[15] R.F. Mager, Preparing Instructional Objectives: A Critical Tool in the Development of Effective Instruction, 3rd ed. Atlanta, GA: Center for Effective Performance, 1997

[16] R.M. Felder and LK.. Silverman, "Learning and teaching styles in engineering education," Engineering Education, vol. 78, no. 7, pp. 674$681,1988$.

[17] D.A. Bligh, What's the Use of Lectures? Jossey-Bass Higher and Adult Education, 2000.

[18] L.T. Benjamin Jr., "Lecturing.," in The Teaching of Psychology: Essays in Honor of Wilbert J. McKeachie and Charles L. Brewer, S.F. Davis and W. Buskist (Eds.). Mahwah, NJ: Lawrence Erlbaum Associates, Inc., 2002, pp. 57-67.

[19] P.C. Wankat, The Effective, Efficient Professor: Teaching, Scholarship and Service. Boston: Allyn \& Bacon, 2002.

[20] K. Wilson and J.H. Korn, "Attention during lectures: beyond ten minutes," Teaching of Psychology ,vol. 34, no. 2, pp. 85-89, April 2007.

[21] C.C. Bonwell and J.A. Eison, Active Learning: Creating Excitement in the Classroom, ASHE-ERIC Higher Education Report No.1, Washington, D.C., The Geroge Washington University, School of Education and Human Development, 1991.

[22] G.B. Wright, "Student-centered learning in higher education," International Journal of Teaching and Learning in Higher Education, vol. 23, no. 3, pp. 92-97, 2011.

[23] M. Baeten, E. Kyndt, K. Struyven and F. Dochy, "Using student-centred learning environments to stimulate deep approaches to learning: Factors encouraging or discouraging their effectiveness," Educational Research Review, vol. 5, no. 3, pp. 243-260, 2010

[24] Ramsden, P. (1992). Learning to teach in higher education. London: Routledge.

[25] R.M. Felder and R. Brent, "Designing and teaching courses to satisfy the ABET engineering criteria," Journal of Engineering Education, vol. 92, no. 1, pp. 7-25, January 2003.

[26] I.M. João and J.M. Silva, "Student engagement with statistical design of experiments by active learning projects,"in $2^{\text {nd }}$ International Conference on Higher Education Advances, HEAd'16, Universitat Politecnica de Valencia, Valencia, 2016.

[27] J. Antony and N. Capon, "Teaching experimental design techniques to industrial engineers," International Journal of Engineering Education, vol. 14, no. 5, pp. 335-343, 1998

[28] D. Skiba and A. Barton, "Adapting your teaching to accommodate the net generation of learners," OJIN: The Online Journal of Issues in Nursing, vol. 11, no. 2, manuscript 4, May 31, 2006. 